\title{
Correction to: Therapeutic application of the CRISPR system: current issues and new prospects
}

\author{
Minyoung Lee ${ }^{1} \cdot$ Hyongbum Kim ${ }^{2}$
}

Published online: 1 June 2019

○) Springer-Verlag GmbH Germany, part of Springer Nature 2019

\section{Correction to: Human Genetics \\ https://doi.org/10.1007/s00439-019-02028-2}

In Original article publication, the Acknowledgment statement was not included. The acknowledgement of this article is given below:

M.Y.L. is supported by Seok-San Biomedical Science Scholarships, Yonsei University College of Medicine. This work was, in part, supported by the Yonsei University Futureleading Research Initiative of 2015 (RMS2 2015-22-0092; Challenge Grant).

Publisher's Note Springer Nature remains neutral with regard to jurisdictional claims in published maps and institutional affiliations.

The original article can be found online at https://doi.org/10.1007/ s00439-019-02028-2.

Minyoung Lee

matt1120@yonsei.ac.kr

Hyongbum Kim

hkim1@yuhs.ac

1 Yonsei University College of Medicine, Seoul 03722, Republic of Korea

2 Department of Pharmacology, Yonsei University College of Medicine, Seoul 03722, Republic of Korea 